OPEN ACCESS

Edited by:

Haibin Shi,

Soochow University, China

Reviewed by:

Min Yang,

Jiangsu Institute of Nuclear Medicine, China

Yao Sun,

Central China Normal

University, China

*Correspondence:

Fang $\mathrm{Li}$

lifang@pumch.cn

Specialty section: This article was submitted to

Cancer Imaging and Image-directed Interventions,

a section of the journal

Frontiers in Oncology

Received: 10 October 2021 Accepted: 22 November 2021 Published: 15 December 2021

Citation:

Jin X, Dong C, Zheng K, Shi X, Liu Y, Huo L, Wang $F$ and Li F (2021)

Scintigraphic Imaging of Neovascularization With ${ }^{99 m} T_{C}$ -

$3 P R G D_{2}$ for Evaluating Early Response

to Endostar Involved Therapies on Pancreatic Cancer Xenografts In Vivo.

Front. Oncol. 11:792431. doi: 10.3389/fonc.2021.792431

\section{Scintigraphic Imaging of} Neovascularization With ${ }^{99 \mathrm{~m}}$ Tc$3 \mathrm{PRGD}_{2}$ for Evaluating Early Response to Endostar Involved Therapies on Pancreatic Cancer Xenografts In Vivo

\author{
Xiaona Jin ${ }^{1,2}$, Chengyan Dong ${ }^{3}$, Kun Zheng ${ }^{1,2}$, Ximin Shi ${ }^{1,2}$, Yu Liu ${ }^{1,2}$, Li Huo ${ }^{1,2}$, \\ Fan Wang ${ }^{4}$ and Fang $\mathrm{Li}^{1,2^{*}}$
}

${ }_{1}^{1}$ Department of Nuclear Medicine, Peking Union Medical College Hospital, Chinese Academy of Medical Sciences and Peking Union Medical College, Beijing, China, ${ }^{2}$ Beijing Key Laboratory of Molecular Targeted Diagnosis and Therapy in Nuclear Medicine, Beijing, China, ${ }^{3}$ GE Healthcare China, Beijing, China, ${ }^{4}$ Medical Isotopes Research Center, Peking University, Beijing, China

Background: Molecular imaging targeting angiogenesis can specifically monitor the early therapeutic effect of antiangiogenesis therapy. We explore the predictive values of an integrin $\alpha v \beta 3$-targeted tracer, $\left.{ }^{99 m} \mathrm{Tc}^{-} \mathrm{PEG}_{4}-\mathrm{E}_{\mathrm{PEG}}-\mathrm{C}(\mathrm{RGDfK})\right]_{2}\left({ }^{99 \mathrm{~m}} \mathrm{Tc}-3 \mathrm{PRGD} \mathrm{D}_{2}\right)$, for monitoring the efficacy of Endostar antiangiogenic therapy and chemotherapy in animal models.

Methods: The pancreatic cancer xenograft mice were randomly divided into four groups, with seven animals in each group and treated in different groups with $10 \mathrm{mg} / \mathrm{kg} / \mathrm{day}$ of Endostar, $10 \mathrm{mg} / \mathrm{kg} /$ day of gemcitabine, $10 \mathrm{mg} / \mathrm{kg} /$ day of Endostar $+10 \mathrm{mg} / \mathrm{kg} /$ day of gemcitabine at the same time, and the control group with $0.9 \%$ saline $(0.1 \mathrm{ml} / \mathrm{day}) .{ }^{99 \mathrm{~m}} \mathrm{Tc}$ $3 P R G D_{2}$ scintigraphic imaging was carried out to monitor therapeutic effects. Microvessel density (MVD) was measured using immunohistochemical staining of the tumor tissues. The region of interest $(\mathrm{ROI})$ of tumor $(\mathrm{T})$ and contralateral corresponding site (NT) was delineated, and the ratio of radioactivity (T/NT) was calculated. Two-way repeatedmeasure analysis of variance (ANOVA) was used to assess differences between treatment groups.

Results: Tumor growth was significantly lower in treatment groups than that in the control group ( $p<0.05)$, and the differences were noted on day 28 posttreatment. The differences of ${ }^{99 m} \mathrm{Tc}-3 \mathrm{PRGD}_{2}$ uptakes were observed between the control group and Endostar group $(p=0.033)$ and the combined treatment group $(p<0.01)$ on day 7 posttreatment and on day 14 posttreatment between the control group and gemcitabine group $(p<0.01)$. The accumulation of ${ }^{99 m} \mathrm{Tc}^{-3 P R G D}$ was significantly correlated with MVD $(r=0.998, p=$ 0.002). 
Conclusion: With ${ }^{99 m} \mathrm{Tc}-3 \mathrm{PRGD}_{2}$ scintigraphic imaging, the tumor response to antiangiogenic therapy, chemotherapy, and the combined treatment can be observed at an early stage of the treatments, much earlier than the tumor volume change. It provides new opportunities for developing individualized therapies and dose optimization.

Keywords: Endostar, ${ }^{99 m T c-3 P R G D}$, antiangiogenesis, scintigraphic imaging, microvessel density

\section{INTRODUCTION}

Inhibition of angiogenesis causes vascular degeneration, hinders the delivery of oxygen and nutrients, and eventually leads to tumor hunger. Antiangiogenic therapy has been approved as an effective strategy to inhibit tumor growth and affect metastatic spread in many countries, providing a novel treatment approach for cancer patients $(1,2)$. As a recombinant human endostatin, Endostar is mainly used for cancer treatment as an antiangiogenic agent $(3,4)$. It was approved by the China Food and Drug Administration (CFDA) for lung cancer treatment in 2005. Endostar has been used in the treatment of a variety of cancers for antiangiogenesis effect, including non-small cell lung cancer, breast cancer, melanoma, and gastric cancer (5-10). Nevertheless, the benefits of Endostar on pancreatic cancer are currently poorly known. Endostar was effective in the treatment of advanced pancreatic neuroendocrine tumors combined with temozolomide or dacarbazine $+5-\mathrm{FU}$, and the combinations were well tolerated (11). Antiangiogenic therapeutics or inhibitors of proangiogenic kinase pathways could antagonize the growth-promoting effect of cantharidin and present additive antitumor effects, exhibiting adequate efficacy. Endostar has shown a good safety profile and tolerance in previous studies, without common toxicity of other VEGF or VEGFR inhibitors, such as hypertension and proteinuria $(6,12-15)$.

In the past years, clinical trials of antiangiogenic therapy with anti-VEGF (bevacizumab) or anti-VEGFR (sorafenib, axitinib) for pancreatic cancer have been carried out (16-20). As often observed in clinical trials, only some patients benefit from treatment $(21,22)$. Therefore, there is an urgent need to develop an alternative approach to select patients who will benefit from antiangiogenic therapies, detect emerging drug resistance, and monitor early treatment outcomes (23).

A histopathologic evaluation of microvessel density (MVD) has been suggested as a prognostic indicator of progression, but it is not suitable for repeated evaluation of tumor angiogenesis because of the invasive nature of the procedure (24). Noninvasive imaging techniques such as dynamic contrast-enhanced (DCE) magnetic resonance imaging (MRI) or computed tomography (CT) can evaluate tumor blood flow and volume but have limited capability to quantify the changes of tumor vessels after treatment (25-27). Positron emission tomography (PET) has been used to monitor antiangiogenic therapy by measuring glucose metabolism changes with approp ${ }^{18} \mathrm{~F}$-FDG (2-deoxy-2-18F-fluoro-D-glucose), but ${ }^{18} \mathrm{~F}$ FDG may not be an appropriate modality as a non-specific tracer. Therefore, molecular imaging targeting specific pathways related to angiogenesis is necessary to specifically monitor some molecular sequence. As an early treatment effect, its advantage is to allow repeated non-invasive follow-ups in the treatment process $(28,29)$.
Integrin $\alpha v \beta 3$ imaging may provide a new method for evaluating tumor angiogenesis and monitoring the response to antiangiogenic therapy (28). The Arg-Gly-Asp (RGD) sequence was known to be associated with integrins expressed on the surface of angiogenic vessels or tumor cells $\alpha v \beta 3$ (30). Thus, various radiolabeled derivatives of RGD peptides have been developed for angiogenesis imaging by PET imaging, such as ${ }^{18} \mathrm{~F}_{-\mathrm{FPRGD}}$ and ${ }^{68} \mathrm{Ga}-\mathrm{NOTA}-\mathrm{PRGD}_{2}$, and single-photon emission computed tomography (SPECT) imaging for the diagnosis of cancers, such as ${ }^{99 m} \mathrm{Tc}^{-3} \mathrm{PRGD}_{2}$ (31-35). RGDbased PET tracers have been evaluated to be comparable to ${ }^{18} \mathrm{~F}$ FDG for lesion detection in clinical studies, with high specificity and long tumor retention. Especially for gliomas and brain metastases, PET imaging with RGD analogues showed a much higher tumor-to-background than ${ }^{18} \mathrm{~F}-\mathrm{FDG}$ did $(36-38) .{ }^{68} \mathrm{Ga}$ $3 \mathrm{PRGD}_{2}$ PET reflected the tumor response to Endostar antiangiogenic therapy much earlier and more accurately than did ${ }^{18}$ F-FDG metabolic imaging (31-35). Compared with the tracers for PET, ${ }^{99 m}$ Tc-3PRGD 2 is a SPECT tracer with wider availability, especially in underdeveloped areas. Because of its simple, efficient, and repeatable preparation procedure, ${ }^{99 \mathrm{~m}} \mathrm{Tc}$ $3 \mathrm{PRGD}_{2}$ is easy for routine clinical use $(39,40)$.

We tried to evaluate the value of ${ }^{99 m} \mathrm{Tc}-3 \mathrm{PRGD}_{2}$ as a binding integrin $\alpha_{\mathrm{v}} \beta_{3}$ imaging agent in monitoring the efficacy of Endostar antiangiogenesis therapy and chemotherapy in animal models, to find a specific way for early monitoring the therapeutic effects and evaluating the follow-ups during the whole therapy. In this study, we also involved gemcitabine, the standard of care for the first-line treatment of metastatic pancreatic cancer globally, to further evaluate the capability of ${ }^{99 m} \mathrm{Tc}-3 \mathrm{PRGD}_{2}$ in treatment monitoring $(39,40)$.

\section{METHOD}

\section{Radiopharmaceutical Preparation}

Synthesis of the labeling precursor, kit preparation, and subsequent ${ }^{99 \mathrm{~m}} \mathrm{Tc}$-labeling were performed as previously described (35). Briefly, the kit for the preparation of ${ }^{99 m} \mathrm{Tc}-3 \mathrm{PRGD}_{2}$ was formulated by combining $20 \mathrm{mg}$ of hydrazinonicotinamide$3 \mathrm{PRGD}_{2}, 5 \mathrm{mg}$ of trisodium triphenylphosphine-3,39,399trisulfonate (TPPTS), $6.5 \mathrm{mg}$ of tricine, $40 \mathrm{mg}$ of mannitol, 38.5 $\mathrm{mg}$ of disodium succinate hexahydrate, and $12.7 \mathrm{mg}$ of succinic acid. For ${ }^{99 \mathrm{~m}}$ Tc radiolabeling, to the kit vial was added $1 \mathrm{ml}$ of 1.110 $1.850 \mathrm{MBq}(30-50 \mathrm{mCi})$ of ${ }^{99 m} \mathrm{TcO}_{4}^{-}$saline solution, and then the vial was water-bathed at $100^{\circ} \mathrm{C}$ for $15-20$ min [MS data shown in previous article ref. (33)]. The resulting solution was analyzed by instant thin-layer chromatography using Gelman Sciences silica-gel 
paper strips and a 1:1 mixture of acetone and saline as eluant. The radiochemical purity was always greater than $95 \%$. The reaction mixture was then diluted to approximately $370 \mathrm{MBq} / \mathrm{ml}(10 \mathrm{mCi} /$ $\mathrm{ml}$ ) with saline and was filtered with a 0.20 -mm Millex-LG filter (EMD Millipore). Each animal was injected with 7.4-11.1 MBq $(0.2-0.3 \mathrm{mCi})$ of ${ }^{99 \mathrm{~m}} \mathrm{Tc}-3 \mathrm{PRGD}_{2}$ per mouse.

\section{Animal Model Establishment}

Female BALB/c mice (5 weeks of age) were purchased from Vital River Lab Animal Technology Co., Ltd. The PANC-1 mouse model was established by subcutaneous injection of $2 \times 10^{6}$ PANC-1 cells into the right shoulders of mice. Once the tumor diameter reached 5-7 $\mathrm{mm}$, the mice were initiated with treatment ( 2 weeks after inoculation of PANC-1 cells).

\section{Treatment Protocols}

The study flowchart is given in Figure 1. PANC-1 tumor-bearing $\mathrm{BALB} / \mathrm{c}$ mice with a tumor size of $5-7 \mathrm{~mm}$ were randomly divided into four groups ( $\mathrm{n}=7$ mice per group). The first group was intraperitoneally injected with $10 \mathrm{mg} / \mathrm{kg}$ Endostar, the second group was intraperitoneally injected with $10 \mathrm{mg} / \mathrm{kg}$ gemcitabine, the third group was intraperitoneally injected with $10 \mathrm{mg} / \mathrm{kg}$ Endostar, and $10 \mathrm{mg} / \mathrm{kg}$ gemcitabine at the same time and $0.9 \%$ saline were used as the negative control. The treatments were performed daily for 28 days continuously. The tumor size was measured daily with a digital caliper, and the formula (volume $=1 / 2$ length $\times$ width $\times$ width) was used to calculate the tumor volume. Body weight was monitored daily to assess potential toxicity. All mice were euthanized, and the tumor tissues were harvested for further immunohistochemical staining when the treatment was complete.

\section{Imaging Protocol}

The scanner was a dual-head $\gamma$-camera (Siemens e.cam, Germany), using low-energy high-resolution collimators and a
$20 \%$ energy window centered on $140 \mathrm{keV}$. Static planar scans of the mice were obtained at $1.5 \mathrm{~h}$ postinjection (p.i.) under isoflurane anesthesia. The acquisition count was $3 \times 10^{5}$. The matrix is $256 \times 256$, and the magnification is 1.33 . The regions of interest (ROIs) of the tumor (T) and non-target (NT, contralateral muscles) were delineated, and the ratios of radioactivity (T/NT) were calculated. The study flowchart is given in Figure 1.

\section{Immunohistochemical Studies}

Using formalin-fixed paraffin-embedded tissue sections and the envision method, CD31-stained slides were examined under appropriate pretreatment to determine MVD in tumor tissue samples. Pathologists selected representative specimens according to the quality and quantity of embedded tissues. On the CD31stained slides, microvessel density was counted in three fields at a magnification of $\times 200$. Microvessel counts were considered to be all round, oval, or irregular structures with positive staining, which were separated from other contour or connective tissue elements. Vessels with muscularis and necrotic areas were excluded.

\section{Statistical Analysis}

Quantitative and semiquantitative data were expressed as the mean \pm SD and analyzed using SPSS version 17.0 (IBM, Chicago, IL, USA). Mean values were compared using one-way analysis of variance (ANOVA) or Student's t-test. Two-way repeatedmeasure analysis of variance (ANOVA) was used to evaluate the differences between different treatment groups.

\section{RESULTS}

\section{Effect of Treatments on Tumor Growth}

There was no significant tumor growth inhibition observed in the Endostar or gemcitabine group before day 21 posttreatment,

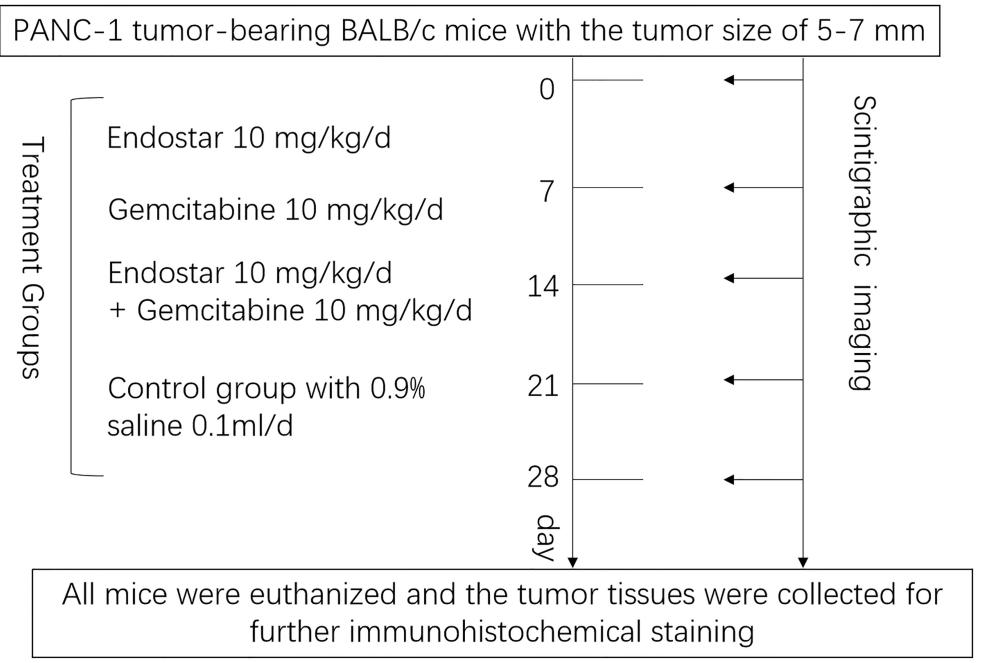

FIGURE 1 | Therapy and imaging protocols. 
compared with the control group ( $\mathrm{p}>0.05)$. The difference between the Endostar + gemcitabine group and the control group was observed on day 14 posttreatment $(\mathrm{p}<0.01)$. At the end of the treatment (day 28 posttreatment), the tumor growth in the control group was rapid with the tumor sizes reaching over $1,881 \pm 523 \mathrm{~mm}^{3}$, but $1,160 \pm 212 \mathrm{~mm}^{3}$ in the Endostar group, $1,171 \pm 496 \mathrm{~mm}^{3}$ in the gemcitabine group, and $801 \pm 399 \mathrm{~mm}^{3}$ in the Endostar + gemcitabine group. There were differences between the treatment groups and the control group $(\mathrm{p}<0.05$, Table 1), demonstrating the tumor growth inhibition effect of treatments. Two-way repeated-measure ANOVA was statistically significant for differences between the three treatment groups and the control group (Table 2 and Figure 2A). Tumor growth was significantly faster in the control group than in all other groups $(\mathrm{p}<0.05)$ and was slower in the Endostar + gemcitabine group than the gemcitabine $(p=0.021)$ and Endostar groups $(p=0.034)$. Treatment was the only regimen that resulted in slowing of the growth of the tumor volume.

\section{Monitoring the Efficacy of Antiangiogenic Therapy by Scintigraphic Imaging}

To monitor the effect of antiangiogenic therapy, scintigraphic imaging was performed by using ${ }^{99 \mathrm{~m}} \mathrm{Tc}-3 \mathrm{PRGD}_{2}$ on days $0,7,14$, 21 , and 28 posttreatment (Figure 3), respectively. At baseline, the tumor uptake values $(\mathrm{T} / \mathrm{NT})$ of ${ }^{99 \mathrm{~m}} \mathrm{Tc}-3 \mathrm{PRGD}_{2}$ were $1.50 \pm 0.08$ (Endostar group), $1.50 \pm 0.17$ (gemcitabine group), $1.52 \pm 0.11$ (Endostar+ gemcitabine group), and $1.55 \pm 0.19$ (control group), and $\mathrm{T} / \mathrm{NT}$ in treatment groups at this time had no significant difference compared to the control group. On day 7 posttreatment, T/NT in the Endostar group was significantly lower than that in the control group $(1.67 \pm 0.16$ vs. $1.87 \pm 0.15$, $\mathrm{p}=0.033$ ), and the difference lasted until the end of treatment (Table 1). The difference was also observed between the control group and the Endostar + gemcitabine group. Moreover, the difference between the gemcitabine group and the control group was observed on day 14 posttreatment. For the therapeutic effect evaluated by T/NT (Figure 2B), two-way repeated-measure ANOVA was statistically significant for differences between the three treatment groups and the control group, shown in Table 2. The T/NT rise was significantly faster in the control group than in all other groups $(\mathrm{p}<0.05)$ and was slower in the Endostar + gemcitabine group than in the gemcitabine group $(\mathrm{p}=0.005)$, but there was no difference between the Endostar + gemcitabine group and the Endostar group $(\mathrm{p}=0.593)$.

\section{Immunohistochemical Findings}

Twenty-eight specimens were stained with CD31 to correlate with the imaging findings. The microvessel densities (MVD) were $10.5 \pm 1.7,15.3 \pm 2.5,9.7 \pm 1.4$, and $23.1 \pm 2.7$ in the Endostar group, gemcitabine group, Endostar + gemcitabine group, and the control group (Figure 4). ${ }^{99 \mathrm{~m}} \mathrm{Tc}^{\mathrm{T}} 3 \mathrm{PRGD}_{2}$ accumulation was significantly correlated with MVD counted on the CD31-stained slides $(r=0.998, \mathrm{p}=0.002)$. MVD in the treatment groups was significantly lower than in the control group ( $\mathrm{p}<0.05)$. The difference was observed between the Endostar group and the gemcitabine group, but there was no difference between the Endostar group and the Endostar + gemcitabine group.

\section{DISCUSSION}

Pancreatic cancer remains one of the most lethal malignancies, causing a huge incidence rate and mortality worldwide. The 5year survival rate is $10 \%$ in the United States and about $7 \%$ in China, because about $80 \%-85 \%$ of patients have unresectable tumors or metastasis at the time of diagnosis $(41,42)$. The main treatment for patients with advanced disease remains systemic combined chemotherapy (43). Therefore, new effective therapeutic schemes and sensitive evaluation of curative effects by non-invasive imaging methods become highly important. In addition to conventional chemotherapy combinations, multiple trials of antiangiogenic therapy with anti-VEGF (bevacizumab) and anti-VEGFR (sorafenib, axitinib) showed variable results such as positive benefits for patients (44-46) or negative results (15-18, 20). In our study, Endostar was chosen as an antiangiogenic drug for the treatment of pancreatic, alone or combined with gemcitabine. Furthermore, ${ }^{99 \mathrm{~m}} \mathrm{Tc}-3 \mathrm{PRGD}_{2}$ SPECT was used to evaluate the therapeutic effect targeting neovascularization.

The results of the two-way repeated-measure ANOVA showed that all three therapeutic schemes were effective in inhibiting tumor growth. On day 14 posttreatment, the tumor volume of the treated mice in the Endostar + gemcitabine group

TABLE 1 | Unpaired t-test (treatment groups vs. control group).

\begin{tabular}{|c|c|c|c|c|c|c|c|c|c|c|}
\hline \multirow{2}{*}{$\begin{array}{l}\text { Time } \\
\text { Groups }\end{array}$} & \multicolumn{2}{|c|}{ Day 0} & \multicolumn{2}{|c|}{ Day 7} & \multicolumn{2}{|c|}{ Day 14} & \multicolumn{2}{|c|}{ Day 21} & \multicolumn{2}{|c|}{ Day 28} \\
\hline & $\begin{array}{l}\text { Tumor } \\
\text { volume }\end{array}$ & T/NT & $\begin{array}{l}\text { Tumor } \\
\text { volume }\end{array}$ & T/NT & $\begin{array}{l}\text { Tumor } \\
\text { volume }\end{array}$ & T/NT & $\begin{array}{l}\text { Tumor } \\
\text { volume }\end{array}$ & T/NT & $\begin{array}{l}\text { Tumor } \\
\text { volume }\end{array}$ & T/NT \\
\hline Endostar vs. control & $p=0.953$ & $\begin{array}{c}p= \\
0.573\end{array}$ & $p=0.696$ & $\begin{array}{c}p= \\
0.033\end{array}$ & $p=0.143$ & $\mathrm{p}<0.01$ & $p=0.07$ & $\begin{array}{c}p= \\
0.015\end{array}$ & $p<0.01$ & $\mathrm{p}<0.01$ \\
\hline Gemcitabine vs. control & $p=0.917$ & $\begin{array}{c}p= \\
0.630\end{array}$ & $p=0.441$ & $\begin{array}{c}p= \\
0.108\end{array}$ & $p=0.258$ & $p<0.01$ & $p=0.191$ & $\begin{array}{c}p= \\
0.041\end{array}$ & $p=0.023$ & $\begin{array}{c}p= \\
0.044\end{array}$ \\
\hline
\end{tabular}


TABLE 2 | Repeated-measure ANOVA.

\begin{tabular}{|c|c|c|c|c|}
\hline \multirow[t]{2}{*}{ Groups ANOVA } & \multicolumn{2}{|c|}{ Tumor volume } & \multicolumn{2}{|c|}{ T/NT } \\
\hline & $\mathbf{F}$ & $\mathbf{p}$ & $\mathbf{F}$ & $\mathbf{p}$ \\
\hline Endostar vs. control & 5.660 & 0.035 & 12.981 & 0.004 \\
\hline Gemcitabine vs. control & 4.899 & 0.047 & 6.913 & 0.022 \\
\hline Endostar + gemcitabine vs. control & 11.873 & 0.005 & 16.133 & 0.002 \\
\hline Gemcitabine vs. Endostar + gemcitabine & 7.086 & 0.021 & 11.838 & 0.005 \\
\hline Endostar vs. gemcitabine & 0.047 & 0.832 & 4.955 & 0.051 \\
\hline Endostar vs. Endostar + gemcitabine & 5.735 & 0.034 & 0.302 & 0.593 \\
\hline
\end{tabular}

was significantly smaller than that in the control group, but Endostar or gemcitabine did not induce a significant reduction in the slope of tumor growth, as compared to controls. On day 28 posttreatment, in monotherapy groups, the tumor growth was observed to be lower than that in the control group. Endostar blocks VEGF/VEGFR signaling which hinders tumor growth by regulating the degradation of the existing tumor vascular system and preventing tumor regeneration for a long time $(47,48)$, while gemcitabine treatment caused cytotoxic damage, abnormal DNA repair, and apoptosis $(47,48)$. The combination of the two drugs seems to be more effective because of the synergy of the two drugs in two different ways to promote tumor growth.

At the end of the second week, a reduction in ${ }^{99 m} \mathrm{Tc}-3 \mathrm{PRGD}_{2}$ tumor uptake (T/NT) was observed in the mice treated with Endostar alone or combined with gemcitabine, compared with controls, in agreement with a reduction in tumor growth. On day 14 posttreatment, $\mathrm{T} / \mathrm{NT}$ in the gemcitabine group was significantly lower than that in the control group. The results of the two-way repeated-measure ANOVA ensure that the treatment was the regimen that resulted in slowing of the growth of the T/NT. Compared with the tumor volume, the difference of the T/NT between treatment groups and the control group was observed earlier. Moreover, the difference of the T/NT in treatment groups including Endostar appeared earlier than that in the gemcitabine group, which may be caused by the earlier mediation of Endostar on neovascularization reduction.

Endostar inhibits neovascular endothelial cells, resulting in reduced integrin expression and decreased accumulation of specific tracers. The reduction in neovascularization may also occur in gemcitabine. The findings were supported by immunofluorescence staining CD31. MVD in all treatment groups was significantly lower than that in the control group. Interestingly, MVD in the gemcitabine group was higher than those in the Endostar group and the combined therapy group, but there was no difference between the latter two groups, which can be explained with the more aggressive neovascularization reduction of Endostar compared to gemcitabine. T/NT was significantly correlated with MVD. ${ }^{99 m} \mathrm{Tc}-3 \mathrm{PRGD}_{2}$ SPECT could be a non-invasive method for evaluating MVD.

There were some limitations in the study. The tumor is not very small for the convenience of imaging, so a difference between the treatment groups and the control group occurs late. "Vascular normalization" mechanisms in antiangiogenesis had not been studied in this study, because our research focused on monitoring therapeutic effects with SPECT imaging. The ex vivo biodistribution data of ${ }^{99} \mathrm{~m}_{\mathrm{Tc}}-3 \mathrm{PRGD}_{2}$ have been investigated in several articles so we focused on the evaluation of imaging quantification.
A

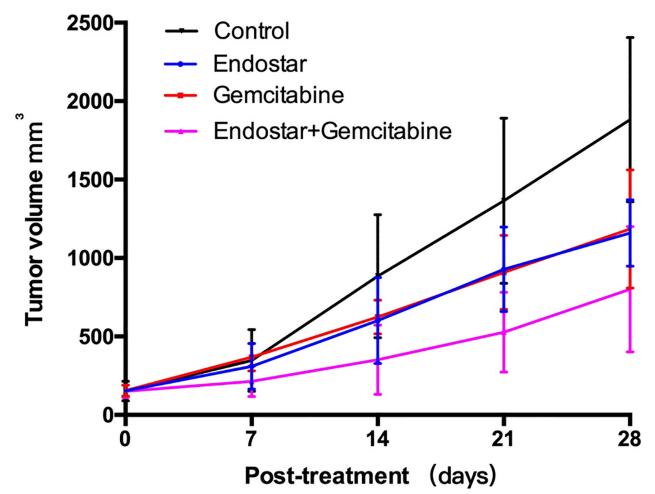

B

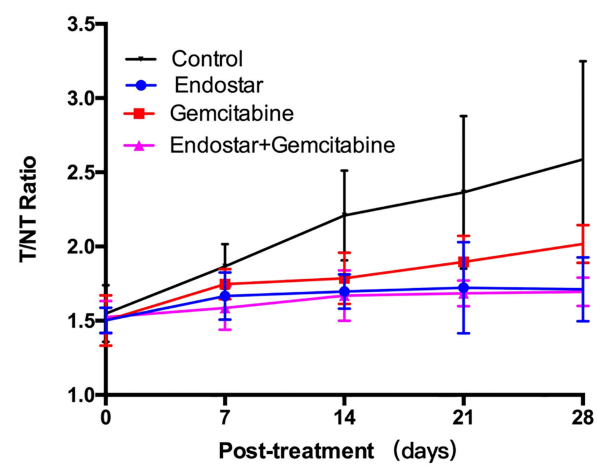

FIGURE 2 | (A) Tumor growth profiles of the control group and treatment groups (7 mice per group). PANC-1 tumor-bearing mice were treated via intraperitoneal injection. Saline-treated animals served as controls. (B) ${ }^{99 m} \mathrm{Tc}-3 P R G D_{2}$ tumor uptake $(T / N)$ in each groups. 
Endostar group

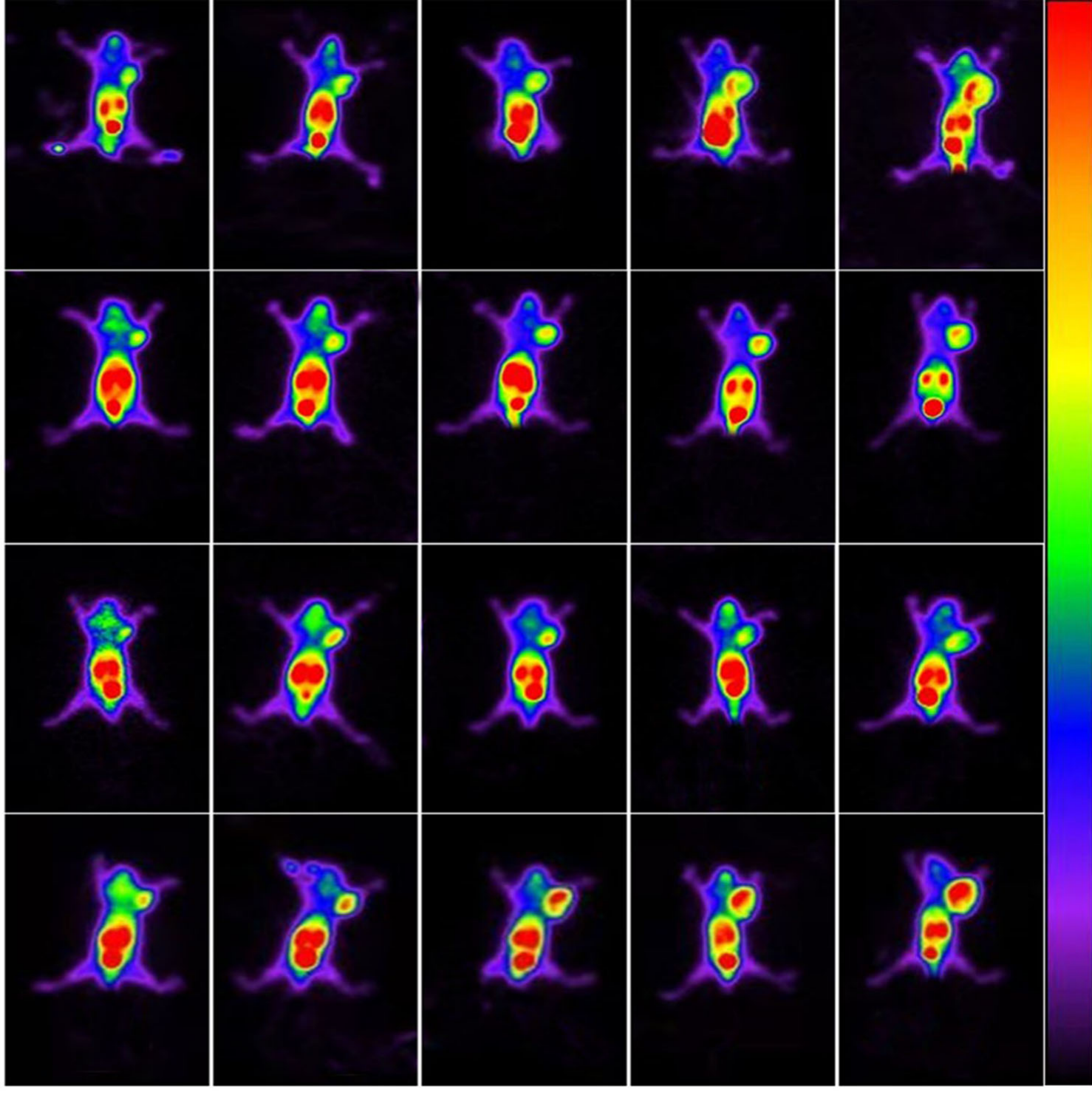

Odays

7days

14days

21days

28days

FIGURE 3 | PANC-1 tumor-bearing mice were imaged with ${ }^{99 m} \mathrm{Tc}^{-3 P R G D}{ }_{2}$ SPECT at days $0,7,14,21$, and 28 post-treatment in the Endostar group, gemcitabine group, combined therapy group, and control group. 


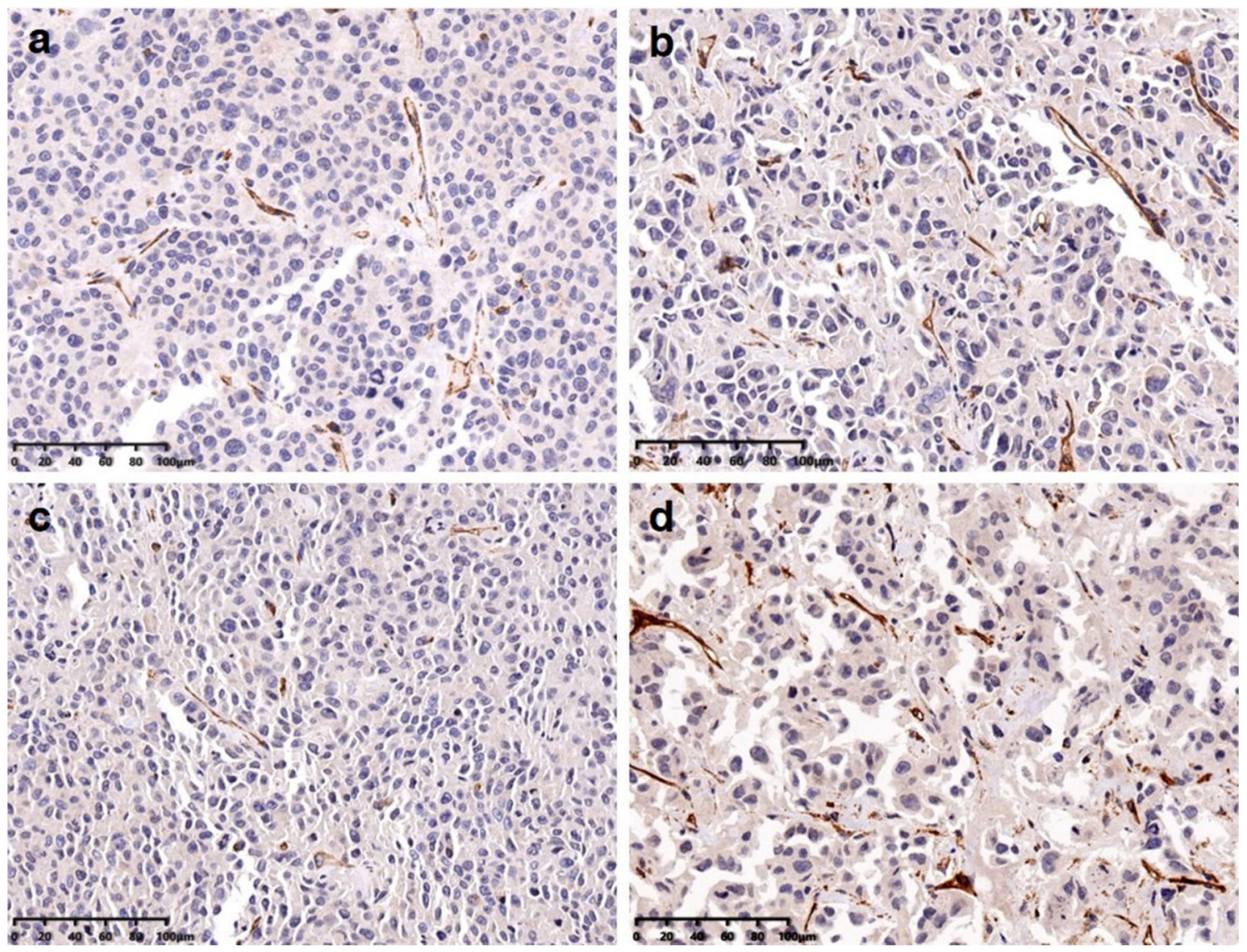

FIGURE 4 | MVD calculated from immunohistochemical stainings in Endostar (A), gemcitabine (B), the combination of those two agents (C), and the control group (D).

\section{CONCLUSIONS}

Using ${ }^{99 \mathrm{~m}} \mathrm{Tc}-3 \mathrm{PRGD}_{2}$ scintigraphic imaging, the response of antiangiogenesis therapies and chemotherapies can be evaluated in the early stage of treatment, much earlier than the change of tumor volume, providing a new opportunity for individualized treatments and dose optimization.

\section{DATA AVAILABILITY STATEMENT}

The original contributions presented in the study are included in the article/supplementary material. Further inquiries can be directed to the corresponding author.

\section{ETHICS STATEMENT}

The animal study was reviewed and approved by the Institute Review Board of Peking Union Medical College Hospital,
Chinese Academy of Medical Sciences, and Peking Union Medical College.

\section{AUTHOR CONTRIBUTIONS}

FL and FW designed the study. YL and CD were responsible for radiosynthesis. $\mathrm{KZ}$ and $\mathrm{XS}$ were responsible for animal studies. LH helped in the study supervision. The manuscript was drafted by XJ and CD. All authors contributed to the article and approved the submitted version.

\section{FUNDING}

This work was financially supported, in part, by the National Natural Science Foundation of China (NSFC) projects (81601551, 81801741, 81671722). 


\section{REFERENCES}

1. Burke PA, DeNardo SJ. Antiangiogenic Agents and Their Promising Potential in Combined Therapy. Crit Rev Oncol Hematol (2001) 39(1-2):155-71. doi: 10.1016/s1040-8428(01)00115-9

2. Folkman J. Antiangiogenesis in Cancer Therapy-Endostatin and Its Mechanisms of Action. Exp Cell Res (2006) 312(5):594-607. doi: 10.1016/ j.yexcr.2005.11.015

3. Ezzell C. Starving Tumors of Their Lifeblood. Sci Am (1998) 279(4):33-4. doi: 10.1038/scientificamerican1098-33

4. Ge W, Cao DD, Wang HM, Jie FF, Zheng YF, Chen Y. Endostar Combined With Chemotherapy Versus Chemotherapy Alone for Advanced NSCLCs: A Meta-Analysis. Asian Pac J Cancer Prev (2011) 12(10):2705-11.

5. Ling Y, Yang Y, Lu N, You QD, Wang S, Gao Y, et al. Endostar, a Novel Recombinant Human Endostatin, Exerts Antiangiogenic Effect via Blocking VEGF-Induced Tyrosine Phosphorylation of KDR/Flk-1 of Endothelial Cells. Biochem Biophys Res Commun (2007) 361(1):79-84. doi: 10.1016/ j.bbrc.2007.06.155

6. Li Y, Huang XE, Yan PW, Jiang Y, Xiang J. Efficacy and Safety of Endostar Combined With Chemotherapy in Patients With Advanced Solid Tumors. Asian Pac J Cancer Prev (2010) 11(4):1119-23.

7. Jia L, Ren S, Li T, Wu J, Zhou X, Zhang Y, et al. Effects of Combined Simultaneous and Sequential Endostar and Cisplatin Treatment in a Mice Model of Gastric Cancer Peritoneal Metastases. Gastroenterol Res Pract (2017) 2017:2920384. doi: 10.1155/2017/2920384

8. Xiao L, Yang S, Hao J, Yuan X, Luo W, Jiang L, et al. Endostar Attenuates Melanoma Tumor Growth via Its Interruption of B-FGF Mediated Angiogenesis. Cancer Lett (2015) 359(1):148-54. doi: 10.1016/ j.canlet.2015.01.012

9. Lu N, Ling Y, Gao Y, Chen Y, Mu R, Qi Q, et al. Endostar Suppresses Invasion Through Downregulating the Expression of Matrix Metalloproteinase-2/9 in MDA-MB-435 Human Breast Cancer Cells. Exp Biol Med (Maywood) (2008) 233(8):1013-20. doi: 10.3181/0801-rm-7

10. Wen QL, Meng MB, Yang B, Tu LL, Jia L, Zhou L, et al. Endostar, a Recombined Humanized Endostatin, Enhances the Radioresponse for Human Nasopharyngeal Carcinoma and Human Lung Adenocarcinoma Xenografts in Mice. Cancer Sci (2009) 100(8):1510-9. doi: 10.1111/j.13497006.2009.01193.x

11. Xu MD, Liu L, Wu MY, Jiang M, Shou LM, Wang WJ, et al. The Combination of Cantharidin and Antiangiogenic Therapeutics Presents Additive Antitumor Effects Against Pancreatic Cancer. Oncogenesis (2018) 7(11):94. doi: 10.1038/s41389-018-0102-2

12. Wang J, Sun Y, Liu Y, Yu Q, Zhang Y, Li K, et al. [Results of Randomized, Multicenter, Double-Blind Phase III Trial of Rh-Endostatin (YH-16) in Treatment of Advanced Non-Small Cell Lung Cancer Patients]. Zhongguo Fei Ai Za Zhi (2005) 8(4):283-90. doi: 10.3779/j.issn.1009-3419.2005.04.07

13. Han B, Xiu Q, Wang H, Shen J, Gu A, Luo Y, et al. A Multicenter, Randomized, Double-Blind, Placebo-Controlled Study to Evaluate the Efficacy of Paclitaxel-Carboplatin Alone or With Endostar for Advanced Non-Small Cell Lung Cancer. J Thorac Oncol (2011) 6(6):1104-9. doi: 10.1097/JTO.0b013e3182166b6b

14. Zhang LP, Liao XY, Xu YM, Yan LJ, Yan GF, Wang XX, et al. Efficacy and Safety of Endostar ${ }^{\circledR}$ Combined With Chemotherapy in Patients With Advanced Soft Tissue Sarcomas. Asian Pac J Cancer Prev (2013) 14 (7):4255-9. doi: 10.7314/apjcp.2013.14.7.4255

15. Rong B, Yang S, Li W, Zhang W, Ming Z. Systematic Review and MetaAnalysis of Endostar (Rh-Endostatin) Combined With Chemotherapy Versus Chemotherapy Alone for Treating Advanced Non-Small Cell Lung Cancer. World J Surg Oncol (2012) 10:170. doi: 10.1186/1477-7819-10-170

16. Van Cutsem E, Vervenne WL, Bennouna J, Humblet Y, Gill S, Van Laethem JL, et al. Phase III Trial of Bevacizumab in Combination With Gemcitabine and Erlotinib in Patients With Metastatic Pancreatic Cancer. J Clin Oncol (2009) 27(13):2231-7. doi: 10.1200/jco.2008.20.0238

17. Kindler HL, Niedzwiecki D, Hollis D, Sutherland S, Schrag D, Hurwitz H, et al. Gemcitabine Plus Bevacizumab Compared With Gemcitabine Plus Placebo in Patients With Advanced Pancreatic Cancer: Phase III Trial of the Cancer and Leukemia Group B (CALGB 80303). J Clin Oncol (2010) 28 (22):3617-22. doi: 10.1200/jco.2010.28.1386
18. Kindler HL, Ioka T, Richel DJ, Bennouna J, Létourneau R, Okusaka T, et al. Axitinib Plus Gemcitabine Versus Placebo Plus Gemcitabine in Patients With Advanced Pancreatic Adenocarcinoma: A Double-Blind Randomised Phase 3 Study. Lancet Oncol (2011) 12(3):256-62. doi: 10.1016/s1470-2045(11)70004-3

19. Gonçalves A, Gilabert M, François E, Dahan L, Perrier H, Lamy R, et al. BAYPAN Study: A Double-Blind Phase III Randomized Trial Comparing Gemcitabine Plus Sorafenib and Gemcitabine Plus Placebo in Patients With Advanced Pancreatic Cancer. Ann Oncol (2012) 23(11):2799-805. doi: 10.1093/annonc/mds135

20. Rougier P, Riess H, Manges R, Karasek P, Humblet Y, Barone C, et al. Randomised, Placebo-Controlled, Double-Blind, Parallel-Group Phase III Study Evaluating Aflibercept in Patients Receiving First-Line Treatment With Gemcitabine for Metastatic Pancreatic Cancer. Eur J Cancer (2013) 49 (12):2633-42. doi: 10.1016/j.ejca.2013.04.002

21. Sennino B, McDonald DM. Controlling Escape From Angiogenesis Inhibitors. Nat Rev Cancer (2012) 12(10):699-709. doi: 10.1038/nrc3366

22. Scott BJ, Quant EC, McNamara MB, Ryg PA, Batchelor TT, Wen PY. Bevacizumab Salvage Therapy Following Progression in High-Grade Glioma Patients Treated With VEGF Receptor Tyrosine Kinase Inhibitors. Neuro Oncol (2010) 12(6):603-7. doi: 10.1093/neuonc/nop073

23. Sessa C, Guibal A, Del Conte G, Rüegg C. Biomarkers of Angiogenesis for the Development of Antiangiogenic Therapies in Oncology: Tools or Decorations? Nat Clin Pract Oncol (2008) 5(7):378-91. doi: 10.1038/ ncponc 1150

24. Foote RL, Weidner N, Harris J, Hammond E, Lewis JE, Vuong T, et al. Evaluation of Tumor Angiogenesis Measured With Microvessel Density (MVD) as a Prognostic Indicator in Nasopharyngeal Carcinoma: Results of RTOG 9505. Int J Radiat Oncol Biol Phys (2005) 61(3):745-53. doi: 10.1016/ j.ijrobp.2004.07.694

25. Morgan B, Thomas AL, Drevs J, Hennig J, Buchert M, Jivan A, et al. Dynamic Contrast-Enhanced Magnetic Resonance Imaging as a Biomarker for the Pharmacological Response of PTK787/ZK 222584, an Inhibitor of the Vascular Endothelial Growth Factor Receptor Tyrosine Kinases, in Patients With Advanced Colorectal Cancer and Liver Metastases: Results From Two Phase I Studies. J Clin Oncol (2003) 21(21):3955-64. doi: 10.1200/ jco.2003.08.092

26. Akisik MF, Sandrasegaran K, Bu G, Lin C, Hutchins GD, Chiorean EG Pancreatic Cancer: Utility of Dynamic Contrast-Enhanced MR Imaging in Assessment of Antiangiogenic Therapy. Radiology (2010) 256(2):441-9. doi: 10.1148/radiol.10091733

27. Bradley DP, Tessier JL, Checkley D, Kuribayashi H, Waterton JC, Kendrew J, et al. Effects of AZD2171 and Vandetanib (ZD6474, Zactima) on Haemodynamic Variables in an SW620 Human Colon Tumour Model: An Investigation Using Dynamic Contrast-Enhanced MRI and the Rapid Clearance Blood Pool Contrast Agent, P792 (Gadomelitol). NMR Biomed (2008) 21(1):42-52. doi: 10.1002/nbm.1161

28. Haubner R, Wester HJ. Radiolabeled Tracers for Imaging of Tumor Angiogenesis and Evaluation of Anti-Angiogenic Therapies. Curr Pharm Des (2004) 10(13):1439-55. doi: 10.2174/1381612043384745

29. Cui Y, Liu H, Liang S, Zhang C, Cheng W, Hai W, et al. The Feasibility of 18FAlF-NOTA-PRGD2 PET/CT for Monitoring Early Response of Endostar Antiangiogenic Therapy in Human Nasopharyngeal Carcinoma Xenograft Model Compared With 18F-FDG. Oncotarget (2016) 7(19):27243-54. doi: 10.18632/oncotarget.8402

30. Haubner R, Wester HJ, Reuning U, Senekowitsch-Schmidtke R, Diefenbach B, Kessler $\mathrm{H}$, et al. Radiolabeled Alpha(V)Beta3 Integrin Antagonists: A New Class of Tracers for Tumor Targeting. J Nucl Med (1999) 40(6):1061-71.

31. Provost C, Rozenblum-Beddok L, Nataf V, Merabtene F, Prignon A, Talbot JN. [(68)Ga]RGD Versus [(18)F]FDG PET Imaging in Monitoring Treatment Response of a Mouse Model of Human Glioblastoma Tumor With Bevacizumab and/or Temozolomide. Mol Imaging Biol (2019) 21(2):297305. doi: 10.1007/s11307-018-1224-9

32. Rasmussen T, Follin B, Kastrup J, Brandt-Larsen M, Madsen J, Emil Christensen T, et al. Angiogenesis PET Tracer Uptake ((68)Ga-NODAGA$\left.\mathrm{E}[(\mathrm{cRGDyK})]_{2}\right)$ in Induced Myocardial Infarction and Stromal Cell Treatment in Minipigs. Diagnostics (Basel) (2018) 8(2):33. doi: 10.3390/ diagnostics 8020033 
33. Yan B, Fu T, Liu Y, Wei W, Dai H, Fang W, et al. 99mTc-3PRGD2 SinglePhoton Emission Computed Tomography/Computed Tomography for the Diagnosis of Choroidal Melanoma: A Preliminary STROBE-Compliant Observational Study. Medicine (Baltimore) (2018) 97(40):e12441. doi: 10.1097/md.0000000000012441

34. Zhu Z, Miao W, Li Q, Dai H, Ma Q, Wang F, et al. 99mTc-3PRGD2 for Integrin Receptor Imaging of Lung Cancer: A Multicenter Study. J Nucl Med (2012) 53(5):716-22. doi: 10.2967/jnumed.111.098988

35. Jin $X$, Liang $N$, Wang $M$, Meng $Y$, Jia $B$, Shi $X$, et al. Integrin Imaging With (99m)Tc-3PRGD2 SPECT/CT Shows High Specificity in the Diagnosis of Lymph Node Metastasis From Non-Small Cell Lung Cancer. Radiology (2016) 281(3):958-66. doi: 10.1148/radiol.2016150813

36. Minamimoto R, Jamali M, Barkhodari A, Mosci C, Mittra E, Shen B, et al. Biodistribution of the ${ }^{18} \mathrm{~F}-\mathrm{FPPRGD}_{2}$ PET Radiopharmaceutical in Cancer Patients: An Atlas of SUV Measurements. Eur J Nucl Med Mol Imaging (2015) 42(12):1850-8. doi: 10.1007/s00259-015-3096-4

37. Wan W, Guo N, Pan D, Yu C, Weng Y, Luo S, et al. First Experience of 18FAlfatide in Lung Cancer Patients Using a New Lyophilized Kit for Rapid Radiofluorination. J Nucl Med (2013) 54(5):691-8. doi: 10.2967/ jnumed.112.113563

38. Mi B, Yu C, Pan D, Yang M, Wan W, Niu G, et al. Pilot Prospective Evaluation of (18)F-Alfatide II for Detection of Skeletal Metastases. Theranostics (2015) 5 (10):1115-21. doi: 10.7150/thno.12938

39. Jia B, Liu Z, Zhu Z, Shi J, Jin X, Zhao H, et al. Blood Clearance Kinetics, Biodistribution, and Radiation Dosimetry of a Kit-Formulated Integrin $\alpha v \beta 3$ Selective Radiotracer 99mTc-3PRGD 2 in Non-Human Primates. Mol Imaging Biol (2011) 13(4):730-6. doi: 10.1007/s11307-010-0385-y

40. Ma Q, Ji B, Jia B, Gao S, Ji T, Wang X, et al. Differential Diagnosis of Solitary Pulmonary Nodules Using ${ }^{99} \mathrm{mTc}-3 \mathrm{p}_{4}-\mathrm{RGD}_{2}$ Scintigraphy. Eur J Nucl Med Mol Imaging (2011) 38(12):2145-52. doi: 10.1007/s00259-011-1901-2

41. Siegel RL, Miller KD, Jemal A. Cancer Statistics, 2020. CA Cancer J Clin (2020) 70(1):7-30. doi: 10.3322/caac.21590

42. Viale PH. The American Cancer Society's Facts \& Figures: 2020 Edition. J Adv Pract Oncol (2020) 11(2):135-6. doi: 10.6004/jadpro.2020.11.2.1

43. Mizrahi JD, Surana R, Valle JW, Shroff RT. Pancreatic Cancer. Lancet (2020) 395(10242):2008-20. doi: 10.1016/s0140-6736(20)30974-0

44. Xiong HQ, Rosenberg A, LoBuglio A, Schmidt W, Wolff RA, Deutsch J, et al. Cetuximab, a Monoclonal Antibody Targeting the Epidermal Growth Factor
Receptor, in Combination With Gemcitabine for Advanced Pancreatic Cancer: A Multicenter Phase II Trial. J Clin Oncol (2004) 22(13):2610-6. doi: $10.1200 /$ jco.2004.12.040

45. Kindler HL, Friberg G, Singh DA, Locker G, Nattam S, Kozloff M, et al. Phase II Trial of Bevacizumab Plus Gemcitabine in Patients With Advanced Pancreatic Cancer. J Clin Oncol (2005) 23(31):8033-40. doi: 10.1200/ jco.2005.01.9661

46. Yang Z, Kang M, Zhu S, Huang J, Li X, Wang R. Clinical Evaluation of Vascular Normalization Induced by Recombinant Human Endostatin in Nasopharyngeal Carcinoma via Dynamic Contrast-Enhanced Ultrasonography. Onco Targets Ther (2018) 11:7909-17. doi: 10.2147/ott.S181842

47. Inai $\mathrm{T}$, Mancuso $\mathrm{M}$, Hashizume $\mathrm{H}$, Baffert F, Haskell A, Baluk $\mathrm{P}$, et al. Inhibition of Vascular Endothelial Growth Factor (VEGF) Signaling in Cancer Causes Loss of Endothelial Fenestrations, Regression of Tumor Vessels, and Appearance of Basement Membrane Ghosts. Am J Pathol (2004) 165(1):3552. doi: 10.1016/s0002-9440(10)63273-7

48. Rofstad EK, Gaustad JV, Egeland TA, Mathiesen B, Galappathi K. Tumors Exposed to Acute Cyclic Hypoxic Stress Show Enhanced Angiogenesis, Perfusion and Metastatic Dissemination. Int J Cancer (2010) 127(7):153546. doi: $10.1002 /$ ijc. 25176

Conflict of Interest: The authors declare that the research was conducted in the absence of any commercial or financial relationships that could be construed as a potential conflict of interest.

Publisher's Note: All claims expressed in this article are solely those of the authors and do not necessarily represent those of their affiliated organizations, or those of the publisher, the editors and the reviewers. Any product that may be evaluated in this article, or claim that may be made by its manufacturer, is not guaranteed or endorsed by the publisher.

Copyright (C) 2021 Jin, Dong, Zheng, Shi, Liu, Huo, Wang and Li. This is an openaccess article distributed under the terms of the Creative Commons Attribution License (CC BY). The use, distribution or reproduction in other forums is permitted, provided the original author(s) and the copyright owner(s) are credited and that the original publication in this journal is cited, in accordance with accepted academic practice. No use, distribution or reproduction is permitted which does not comply with these terms. 